\title{
Actual Birth Weight Versus Sonographic Estimation of Fetal Weight
} \author{
SIDDIQUI ${ }^{6}$, MURAD QADIR ${ }^{7}$ \\ ${ }^{1}$ Assistant Professor Obstetrics and Gynecology, United Medical and Dental College, Karachi \\ ${ }^{2}$ Assistant Professor Community Health Sciences, United Medical and Dental College, Karachi \\ ${ }^{3}$ Senior Registrar Obstetrics and Gynecology, United Medical and Dental College, Karachi \\ ${ }^{4}$ Associate Professor Obstetrics and Gynecology, United Medical and Dental College, Karachi \\ ${ }^{5}$ Assistant Professor Radiology Department, United Medical and Dental College, Karachi \\ ${ }^{6}$ Professor, Obstetrics and Gynecology, United Medical and Dental College, Karachi \\ ${ }^{7}$ Professor, Community Health Sciences, United Medical and Dental College, Karachi \\ Corresponding author: Saba Pario, E-mail address: drsabapario@gmail.com
}

SABA PARIO ${ }^{1}$, GHAZALA NASIM PASHA ${ }^{2}$, SHAISTA BASHIR ANWAR ${ }^{3}$, SADIA SUBOOHI ${ }^{4}$, FARZANA REHMAN ${ }^{5}$, SHAHNAZ HASSAN

\begin{abstract}
Objective: To assess the correlation of fetal weight at full-term pregnancy by ultrasound method and its authenticity with actual birth weight in obstetrics department of Creek general hospital of Karachi.

Methodology: A Prospective cross-sectional study was conducted at Obstetrics and Gynecology department of Creek General hospital affiliated with United Medical and Dental College Karachi from October 2020 to June 2021. Non-Probability Sampling technique was employed. Estimated sample size was $n=114$, however to increase the precision of study 163 samples were collected. All the pregnant singleton women were enrolled in this study who were examined for fetal weight calculation sonographically at $37^{\text {th }}$ to $40^{\text {th }}$ weeks of gestation. Post-natal neonatal weight was recorded.

Results: The mean fetal weight estimated by ultrasound in our survey was $2.9 \mathrm{~kg}$, while mean, actual birth weight was $2.89 \mathrm{Kg}$. Conclusion: Our study found positive association between the actual birth weight and the estimated fetal weight. Keywords: Fetus, Correlation, Mean, Ultrasound, Birth weight
\end{abstract}

\section{INTRODUCTION}

Pakistan has third highest infant mortality rate around the globe ${ }^{1}$. A baby born in Pakistan has one in 22 chance of death, as compared only one in 1,111 in japan 1 fetal weight is an important element influencing obstetrical management ${ }^{1}$.

Fetal weight estimation is a measure which is included in management of pregnancy and delivery world-wide. high risk pregnancy should have fetal weight estimation at term prior to delivery. Among the leading causes of neonatal deaths in developing countries are low-birth weight and prematurity. Estimating fetal weight is very important because both low birth weight and macrosomic fetuses are at risk during delivery and post-delivery ${ }^{1}$.

As weight of fetus predicts status of its survival after birth ${ }^{2}$ Clinical technique for estimating fetal weight is simple, cheap, effective and adequate in estimating fetal weight in clinics located at peripheral areas of emerging countries ${ }^{3}$. The skillful birth attendant (SBA) takes directions from the predicted fetal weight(scans) in deciding the route of delivery ${ }^{4}$. Sonographic estimation of fetal weight is cardinal in management of pregnant women with diabetes, previous cesarean, planned for VBAC and when presenting part is other than vertex ${ }^{3}$.

Sonographic prediction for macrosomic fetus remains limited, with low sensitivity ${ }^{4}$. Obstetric ultrasound is an essential part of the obstetric examination ${ }^{5}$.

Sonographic estimation of fetal weight was earliest presented by Campbell and Wilkin Higginbottom et $\mathrm{al}^{6}$. Sonographic estimation of fetal weight is done by Hadlock's formula calculated by biparietal diameter (BPD), abdominal circumference $(A C)$, and femoral length $(F L)^{2}$. Multiple maternal, fetal, and technical factors may affect the accuracy of estimated fetal weight ${ }^{7}$. The rate of clinically significant error is more when Ultrasound is conducted by an inexperienced person ${ }^{4}$.

Antenatal magnetic resonance imaging (MRI) or soft-tissue measurements have been shown to be of no benefit in improving the accuracy of fetal weight estimation ${ }^{8}$. One of studies concluded that estimation of ultrasound fetal weight and actual birth weight has no significant difference except ultrasound estimation is better for females who weigh heavier than average ${ }^{9}$.

The anticipated fetal weight can be challenged legally for causing trauma to the fetus during birth. This trend is increasing in Germany and other developed nations, although this practice is not strong for there is only weak evidence ${ }^{7}$. Estimation of fetal weight sonographically has been refined recently but lack of consistency remains evident due to untrained persons.
Meticulous audit system can enhance the precision and appraise this technique increasing the training duration for ultrasound of trainee doctors significantly decreases the errors ${ }^{4}$.

This study is first of its kind in this underdeveloped area of Karachi that is Korangi and it will help in management of antenatal patients of this wide area.

\section{METHODOLOGY}

A Prospective cross sectional study was conducted to asses correlation of actual birth weight versus sonographic estimation of birth weight at Obstetrics and Gynecology department of Creek General hospital affiliated with United Medical and Dental College Karachi between October 2020 and June 2021. Non-Probability Sampling technique was employed. informed written consent was taken from all participants. The study was conducted after approval from the Ethical Review Board Committee of our institution.

All the pregnant singleton women were enrolled in this study who were examined for fetal weight calculation sonographically at $37^{\text {th }}$ to $40^{\text {th }}$ weeks of pregnancy. A detailed history and examination were performed in antenatal clinic of Creek general hospital, Karachi. Again, a detailed examination was conducted when these females were admitted for delivery by vaginal or abdominal route. Post-delivery examination including baby's weight was recorded at this time.

Sample Size: By using Open Epi sample size calculator taking confidence interval $95 \%$, relative difference of fetal weight with reference to article ${ }^{10}$ is $92 \%$ with margin of error as $5.0 \%$, then the estimated sample size was $n=114$, however to increase the precision of study 163 samples were collected.

Inclusion Criteria: Pregnant full-term women more than 18 years of age with singleton gestation and vertex presentation not started signs of labor, had prior sonographic fetal weight estimation within one week.

Exclusion Criteria: Fetuses with congenital problems., Multiple gestations., non- vertex presentation, intra-uterine fetal death, excessive or reduced liquor.

Data collection: The data was collected on predesigned Performa. Sonographic examination and fetal weight estimation were performed by consultant radiologist within one week of delivery. Fetal weight was estimated by using "Hadlock 3" formula. Calculations were revised thrice using Hadlock formula: Log 10 birth weight $=1.335-(0.0034 \times$ abdominal circumference $\mathrm{x}$ femur length $)+(0.0316 \times$ biparietal diameter $)+(0.0457 \times$ abdominal circumference $)+(0.1623 \times$ femur length $)$. TOSHIBA xario, real time with convex probe of 3.7-5.7-megahertz frequency was used. 
Birth weight after delivery was recorded in grams by electronic weighing machine within 2 hours of birth.

Statistical Analysis: Data were stored and analyzed using IBMSPSS version 23.0. Counts with percentages were given for baseline characteristics of patients. Mean with standard deviation reported for fetal parameters. Independent sample t-test was used to compare the actual birth and estimated birth weight, Pearson Correlation was also done to study the relationship actual and US birth weight, $p$-values less than 0.05 were considered significant. Pie diagram and bar charts also used to give graphical presentation of data.

\section{RESULTS}

Mean age of patients was calculated to be 25.6 years. Mean gestational age was 38.47 weeks. Mean of parity was $1.15^{\prime}$ Mean sonographically estimated fetal weight was $2.96 \mathrm{~kg}$ and actual fetal weight at birth means was $2.85 \mathrm{~kg}$. A linear correlation was found between actual fetal birth weight and estimated fetal weight ( $p$ value $=0.012$ and $R 2=0.08$ ). In this survey there were one hundred and sixty-three samples, having mean age $25.5(\mathrm{SD}= \pm 4.35)$ years. $46.6 \%$ samples found with age group $25-30$ years old, $37.4 \%$ samples found with zero parity, and $56.5 \%$ have parity $1-3$, regarding mode of delivery , $22.7 \%$ had EMLSCS , $10.5 \%$ found with ELLSCS and $39.9 \%$ had SVD .

Table 1: Baseline Characteristics of Studied Samples $(n=163)$

\begin{tabular}{|c|c|c|c|}
\hline \multirow{5}{*}{\begin{tabular}{|l|} 
Characterisstics \\
Age of patient
\end{tabular}} & & $\mathrm{N}$ & $\%$ \\
\hline & $<20$ & 23 & 14.1 \\
\hline & $20-24$ & 45 & 27.6 \\
\hline & $25-30$ & 76 & 46.6 \\
\hline & $31-40$ & 19 & 11.7 \\
\hline & Mean $\pm S D$ & 25.5 & \pm 4.35 \\
\hline \multirow[t]{3}{*}{ Parity } & 0 & 61 & 37.4 \\
\hline & $1-3$ & 92 & 56.5 \\
\hline & $4-7$ & 10 & 6.1 \\
\hline \multirow[t]{2}{*}{ Gravida } & $1-3$ & 138 & 84.7 \\
\hline & $4-8$ & 25 & 15.4 \\
\hline \multirow[t]{6}{*}{ Mode of delivery } & EMLSCS & 37 & 22.7 \\
\hline & SVD & 65 & 39.9 \\
\hline & SVD WITH EPI & 39 & 23.9 \\
\hline & VACUM & 4 & 2.5 \\
\hline & FORCEPS & 1 & 0.6 \\
\hline & EL LSCS & 17 & 10.4 \\
\hline
\end{tabular}

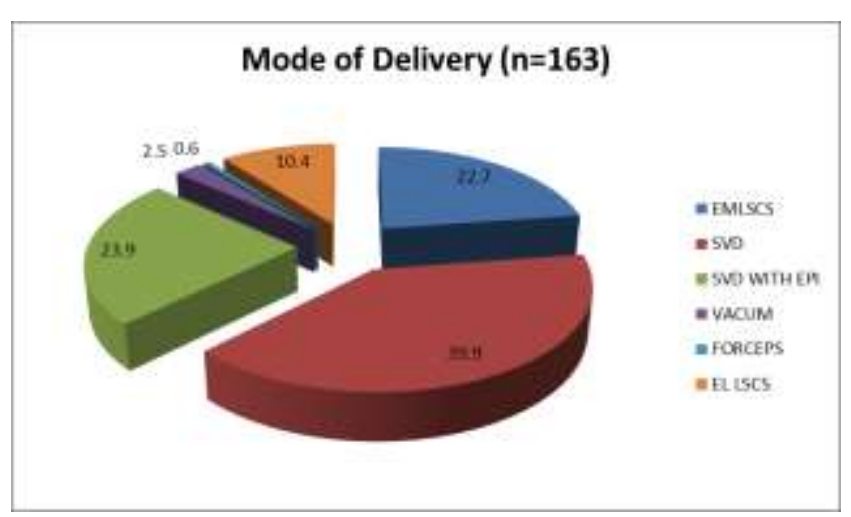

Table-2 report the descriptive measures of fetal parameters, the mean gestational age was found $38.47(S D= \pm 1.09)$ weeks, US weight was $2.96(\mathrm{SD}= \pm 0.42) \mathrm{kg}$, actual $2.85(\mathrm{SD}= \pm 0.43) \mathrm{kg}$.

For male gender the mean gestational age was found 38.5 $(\mathrm{SD}= \pm 1.07)$ weeks, US calculation was $2.94(\mathrm{SD}= \pm 0.42) \mathrm{kg}$, actual was $2.82(\mathrm{SD}= \pm 0.42) \mathrm{kg}$ and APGAR score was 7.15 (SD $= \pm 1.05)$ units, whereas, for female gender the mean gestational age was found $38.45(S D= \pm 1.13)$ weeks, sonographic estimation was $2.99(\mathrm{SD}= \pm 0.44) \mathrm{kg}$ and actual birth weight was $2.89(\mathrm{SD}=$ $\pm 0.45) \mathrm{kg}$ and APGAR score was $7.22(\mathrm{SD}= \pm 0.69)$ units. Independent sample t-test showed there was no statistical difference for mean gestational age, US weight, Actual weight, and APGAR score with respect to gender, $(p>0.05)$.

Table 2: Descriptive statistics of fetal parameters
\begin{tabular}{|l|l|l|l|l|l|l|l|}
\hline Parameters & $\begin{array}{l}\text { Total } \\
(\mathrm{n}=163)\end{array}$ & \multicolumn{3}{l}{$\begin{array}{l}\text { Male } \\
(\mathrm{n}=89)\end{array}$} & \multicolumn{2}{l}{$\begin{array}{l}\text { Female } \\
(\mathrm{n}=74)\end{array}$} & p-value \\
\cline { 2 - 8 } & Mean & SD & Mean & SD & Mean & SD & \\
\hline $\begin{array}{l}\text { Gestational } \\
\text { Age (weeks) }\end{array}$ & 38.47 & 1.09 & 38.5 & 1.07 & 38.45 & 1.13 & 0.81 \\
\hline $\begin{array}{l}\text { US Weight } \\
\text { (kg) }\end{array}$ & 2.96 & 0.42 & 2.94 & 0.42 & 2.99 & 0.44 & 0.47 \\
\hline $\begin{array}{l}\text { Actual Birth } \\
\text { Weight (kg) }\end{array}$ & 2.85 & 0.43 & 2.82 & 0.42 & 2.89 & 0.45 & 0.35 \\
\hline APGAR Score 7.18 & 0.90 & 7.15 & 1.05 & 7.22 & 0.69 & 0.62 \\
\hline p-value was obtained using independent sample t-test & & \\
\hline
\end{tabular}

Table -3 gives the mean comparison sonographic estmated weight and actual birth weight, the mean difference between was 0.10 , that showed actual birth weight was lesser than the estimated birth weight of US, this difference was considered significant with $p$-value 0.02 .

Table 3: Mean Comparison of Actual and US Birth weight

\begin{tabular}{|l|l|l|l|l|}
\hline Parameters & Mean & SD & Mean Difference & -value \\
\hline $\begin{array}{l}\text { Actual Birth } \\
\text { Weight (kg) }\end{array}$ & 2.85 & 0.43 & -0.10 & $0.02^{*}$ \\
\hline US Weight (kg) & 2.96 & 0.42 & & \\
\hline
\end{tabular}

${ }^{*} \mathrm{p}<0.05$ was considered significant using independent sample t-test

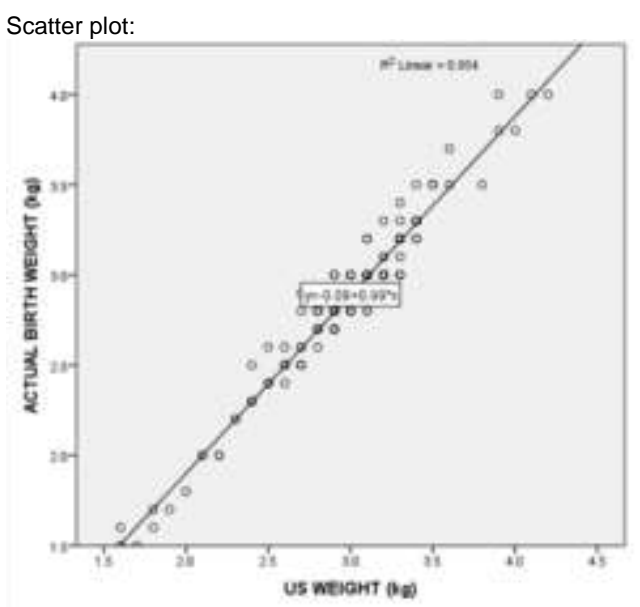

There was positive correlation between US weight and actual birth weight, $r$-square showed $95.4 \%$ variation in actual birth weight was explained by the help of US weight. This was statistically significant with $p$-value less than 0.01 .

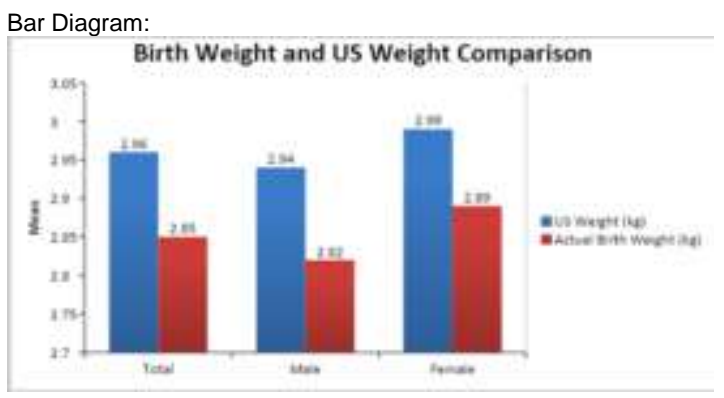

\section{DISCUSSION}

Precise forecast regarding weight of fetus before delivery is of immense importance to an obstetrician. Numerous techniques are employed for this purpose, mainly clinical and ultrasonographic 
methods. Ultrasound is used universally as it is a replicable, imperial method and applies comprehensible measurements.

Although, the accuracy of the outcome is dependent heavily upon the condition of the ultrasound machine and sonologist expertise $^{11}$

The mean age of participants in current study was 25.6 years with standard deviation of \pm 4.35 , the mean gestational age was 38.47 weeks , with standard deviation \pm 1.09 weeks.

Mean of sonographic estimated fetal weight was 2.96 with standard deviation of \pm 0.42 and mean actual birth weight was 2.85 with standard deviation of \pm 0.43 .

A true relationship was observed between sonographic estimated fetal weight and actual birth weight $(p$-value $=0.012$ and $\mathrm{R} 2=0.08$ ). There was non-significant variation among $E F W$ and the ABW. In the mean comparison of sonographic estimated fetal weight and actual birth weight and, the mean variation was -0.10 , that revealed actual birth weight was lesser than the estimated birth weight, this difference was judged meaningful with $p$-value 0.02 .

This study is in consistent with the results of Rashid SQ, et al who observed birth weight of $2817 \pm 783 \mathrm{gm}$ in Bangladesh ${ }^{12}$ and Schild RL et al, also documented birth weight of $2926 \pm$ $1051 \mathrm{gm}$ in Germany but in contrast study conducted in Lahore states, the mean weight of fetus on ultrasound 3187.60 grams and the real weight of baby 3282.32 grams $^{13}$. The average difference found between ultrasound estimated versus newborn weight soon after birth was of 94.72 grams. Another study in Nigeria documented mean birth weight of $3300 \pm 600 \mathrm{gm}$ by Ugwu EO et al ${ }^{14}$. The reason for this difference may be due to variation in regional and socioeconomic factors in different countries.

In another study actual and estimated weight were statistically non-significant $(r=0.778$ Pearson's correlation coefficient and R2 $=0.606$ coefficient of determination) overall there was under estimation $(72.5 \%)$ of fetal weight. Underestimation was $-113.6+/-313(95 \% \mathrm{Cl}-141.3$ to $-85.9 ; \mathrm{P}<0.001){ }^{7}$.

The birth weight mean calculated by clinical method was $3492.75 \pm 393.16 \mathrm{~g}$, sonographically $3230.02 \pm 407.22 \mathrm{~g}$ and true calculated after delivery was $3236.32 \pm 472.87 \mathrm{~g}$ " in one of the studies conducted in Nepal ${ }^{15}$.

A study performed in a private hospital found that $72.54 \%$ of the evaluated weights were under $10 \%$ of the actual birth weight ${ }^{11}$.

One of study performed in South-East Nigeria suggested the fetal weight estimation by ultrasound is accurate ${ }^{9}$. Survey conducted by Tas EE et al, concluded the fetal weight estimated by ultrasound is accepted in majority of health facilities ${ }^{13}$.

Calculating the weight of fetus by the ultrasound method gives better results in case of weight $<2500 \mathrm{gms}^{16}$. In one study, the ultrasound calculations were over-estimated in $15.29 \%$ of the fetuses and under- estimated in $11.76 \%{ }^{7}$.

First pregnancy and fetal presentation by vertex were issues of incorrect results, conversely study conducted by Barel $\mathrm{O}$ et al, states that the parity and presenting part does not have any influence on sonographic fetal weight estimation ${ }^{13}$ no such association was assessed in our study.

For obstetricians, ultrasound has gained a very important place ${ }^{17}$. Ultrasound upgrade the care standard for both obstetrical and non-obstetrical conditions ${ }^{18,19}$

Over the previous decade, predicting the weight of a fetus has been included into the assessment routine of vulnerable pregnancies ${ }^{20}$. Exact calculation of weight of fetus decreases the morbidity and mortality associated with high risk pregnancies ${ }^{20}$. while incorrect prediction might sequel unneeded and avoidable or delayed intrusions, leading to complications and susceptibility to medicolegal problems ${ }^{21}$.

Limitations: Our study was conducted in one health facility of Korangi Karachi due to participants demographic characteristics the results could not be generalized, and bias can occur if applied on general population of Karachi.

\section{CONCLUSION}

There was non-significant variability between sonographic estimation and actual birth weight i.e., < 10\% concluding that weight estimation by ultrasound is reliable and should be done predelivery to detect any complications and prevent its consequences.

Suggestions: Since accuracy for estimation of fetal weight is vital for both fetal and maternal health and planning of delivery , surely ultrasound should be promoted in each health centre.in future the research must be promoted to establish more economical ultrasound specially in poor countries having deficient resource. The estimation should be more accurate and the acceptance of less $10 \%$ error be further reduced because we cannot escape the fact, that weight of fetus is a pillar in maternal and child health.

\section{REFERENCES}

1. Nasir M, Sohail I, Siraj N. Estimated Fetal Weight; A Comparison between Clinical and Ultrasonographical Measurements. J Soc Obstet Gynaecol Pak. 2019; Vol 9(3):135-140.

2. Aruna, et al. Estimation of Fetal Weight by Clinical Methods and Ultrasound and Correlating its Accuracy with Actual Birth Weight in Term Pregnancies. International Journal of Scientific Study | July 2017 | Vol 5 | Issue 4.

3. Roy AG, Kathaley MH. Comparison of Estimation of Fetal Weight by Clinica Me/thod, Ultrasonography and its Correlation with Actual Birth Weight in Term Pregnancy. MVP Jour/nal of Medical Science. 2018 Aug 17;5(1):75-81.

4. Ibrahim AM, Weldetensaye EK. Accuracy of Ultrasound Estimation of Fetal Weight at Three Teaching Hospitals in Addis Ababa. Roy AG, Kathaley MH. Comparison of Estimation of Fetal Weight by Clinical Me/thod, Ultrasonography and its Correlation with Actual Birth Weight in Term Pregnancy. MVP Journal of Medical Science. 2018 Aug 17;5(1):75-81.

5. Kim ET, Singh K, Moran A, Armbruster D, Kozuki N. Obstetric ultrasound use in low- and middle-income countries: a narrative review. Reproductive health. 2018 Dec;15(1):129.

6. Campbell S, Wilkin D. Ultrasonic measurement of fetal abdomen circumference in the estimation of fetal weight. BJOG: An International Journal of Obstetrics \& Gynaecology. 1975 Sep;82(9):689-97.

7. Stubert J, Peschel A, Bolz M, Glass Ä, Gerber B. Accuracy of immediate antepartum ultrasound estimated fetal weight and its impact on mode of delivery and outcome-a cohort analysis. BMC pregnancy and childbirth. 2018 Dec and outcom $1 ; 18(1): 118$

8. Uzma Zahoor et al., Accuracy of Ultrasound Estimated Fetal Weight at Term., IndoAm. J. P. Sci, 2019; 06(07).

9. Preyer, O., Husslein, H., Concin, N. et al. Fetal weight estimation at term ultras/ound versus clinical examination with Leopold's manoeuvres: a prospective blinded observational study. BMC Pregnancy Childbirth 19, 122 (2019)

10. NAZEER N, MEHMOOD A, BAIG MU, ASAD A. Concordance of Sonographic Fetal Weight Estimation and Actual Birth Weight in Pakistani Population Using Hadlock Formula.

11. Okafor CO, Okafor $\mathrm{Cl}$, Mbachu II, Obionwu IC, Aronu ME. Correlation of Ultrasonographic Estimation of Fetal Weight with Actual Birth Weight as Seen in a Private Specialist Hospital in South East Nigeria. International journal of reproductive medicine. 2019 Oct 27;2019.

12. Ferdous, F., Rashid, M.H., Ma, E. et al. Fetal growth restriction in rural Bangladesh: a prospective study. Trop Med Health 46, 3 (2018).

13. Tas EE, Kir EA, Yilmaz G, Yavuz AF. Accuracy of sonographic fetal weight estimation in full-term singleton pregnant women. Pak J Med Sci. 2019;35(1):3438.

14. Onwuka Cl, Ugwu EO, Onah HE, Obi SN, Menuba IE, Okafor II. Patterns of gestational weight gain and its association with birthweight in Nigeria. Nigerian journal of clinical practice. 2017 Jun 28;20(6):754-60.

15. Joshi A, Panta OB, Sharma B. Estimated Fetal Weight: Comparison of Clinica Versus Ultrasound Estim/ate. J Nepal Health Res Counc. 2017 Jan;15(1):51-55.

16. Hughes MM, Black RE, Katz J. 2500-g low birth weight cutoff: history and implications for future research and policy. Maternal and child health journal. 2017 Feb 1;21(2):283-9.

17. Parvin Z, Shafiuddin S, Uddin MA, Begum F. Symphysio fundal height (SFH) measurement as a predictor of birth weight. Faridpur Medical College Journal. 2012;7(2):54-8

18. Dimassi KDF, Ajroudi M, Triki A, Gara MF. Ultrasound Fetal Weight Estimation: How Accurate Are We Now Under Emergency Conditions? Ultrasound Med Biol. 201505.020.

19. Kim ET, Singh K, Moran A, Armbruster D, Kozuki N. Obstetric ultrasound use in low- and middle-income countries: a narrative review. Reproductive health. 2018 Dec;15(1):129.

20. Shapla NR, Aleem MA, Jesmin E, Ahmed H, Lepe YS. Correlation between Estimated Fetal Weight at Term by Ultrasonogram and Actual Birth Weight. Journal of Bangladesh College of Physicians and Surgeons. 2014 Nov Journal of Bang
$30 ; 32(1): 21-5$.

21. Hiwale SS, Misra H, Ulman S. Ultrasonography-based fetal weight estimation finding an appropriate model for an Indian population. Journal of medical ultrasound. 2017 Mar 1;25(1):24-32. 